\title{
14-Thienyl Methylene Matrine (YYJ18), the Derivative from Matrine, Induces Apoptosis of Human Nasopharyngeal Carcinoma Cells by Targeting MAPK and PI3K/Akt Pathways in Vitro
}

\author{
Mao Xie ${ }^{a}$ Xiang Yia Renjun Wang ${ }^{b}$ Lisheng Wang ${ }^{c}$ Guangyao He ${ }^{a}$ Meichan Zhu ${ }^{a}$ \\ Chenglin Qja Yikang Liu ${ }^{\mathrm{a}} \mathrm{Yu} \mathrm{Ye}^{\mathrm{d}}$ Songhua Tan ${ }^{\mathrm{a}}$ Anzhou Tang ${ }^{\mathrm{a}}$ \\ aDepartment of Otolaryngology-Head \& Neck Surgery, First Affiliated Hospital of Guangxi Medical \\ University, Nanning Guangxi, ${ }^{b}$ Department of Otolaryngology-Head \& Neck Surgery, First people's \\ Hospital of Yibin, Yibin Sichuan, 'School of Chemistry and Chemical Engineering, Guangxi University, \\ Nanning, dDepartment of Emergency, First Affiliated Hospital of Guangxi Medical University, Nanning, \\ P.R.China
}

\section{Key Words}

14-thienyl methylene matrine $•$ Nasopharyngeal carcinoma $•$ Apoptosis $•$ MAPK $•$ Akt

\begin{abstract}
Background/Aims: Nasopharyngeal carcinoma (NPC) is a distinctive type of head and neck cancer with the highest incidence in South China. Previous studies have proved that matrine, a main alkaloid isolated from Sophora flavescens Ait, has antitumor activity against NPC. However, the effect is not so pronounced and the underlying mechanism remains largely unclear. Here we investigated whether 14-thienyl methylene matrine (YYJ18) that was derived from matrine could exert more effective suppression activity on NPC, along with the underlying mechanism. Methods: NPC cell lines CNE1, CNE2 and HONE1 were treated with YYJ18. Cell proliferation and apoptosis were determined by MTT assay and flow cytometry. Activation of mitogen-activated protein kinases (MAPK) and phosphatidylinositol 3-kinase/protein kinase B (PI3K/Akt) pathways were determined by Western blotting and quantitative RT-PCR. Results: YYJ18 remarkably inhibited proliferation and induced apoptosis of all three NPC cell lines in a dose-dependent manner, especially in CNE2 cells. Furthermore, YYJ18 treatment significantly suppressed phosphorylation of p38 in CNE2 cells, but upregulated phosphorylation of extracellular signal-regulated kinase1/2 (ERK1/2) and Akt. Next, alterations in downstream signaling were found, including activation of $\mathrm{BCL}$-associated $\mathrm{X}$ protein (Bax), caspase-3 and inactivation of $\mathrm{B}$-cell CLL/lymphoma $2(\mathrm{BCl}-2)$. Conclusion: We demonstrate the potent inhibitory effects of 14-thienyl methylene matrine on NPC cells for the first time, which could be mediated by modulation of MAPK and PI3K/Akt pathways.
\end{abstract}

Copyright $(2014$ S. Karger AG, Basel

Dr. Anzhou Tang 


\section{Introduction}

Nasopharyngeal carcinoma (NPC) is a malignant tumor of head and neck. And it is believed that Epstein-Barr virus (EBV), environmental carcinogens, ethnic background and dietary components all seem to play an important role in the development of NPC [1]. Therefore, NPC displays a characteristic geographical distribution, and is prevalent in Southeast Asia, the Mediterranean basin and the Middle East [2]. Take South China as an example, it is estimated that the annual incidence rate of NPC varies between 15 and 50 cases per 100,000 [3]. The concurrent combination of radiotherapy and chemotherapy has improved the prognosis of patients with NPC, but with severe toxic side effects and relatively low 5 -year survival rate (50\% to $60 \%)$. So the development of effective but less toxic therapies is necessary $[4,5]$.

Sophora flavescens Ait is a well-known Chinese herbal medicine that has been widely used for the clinical treatment of viral hepatitis, atherosclerosis, arrhythmias and cancer in China for thousands of years [6]. As a main alkaloid from Sophora flavescens Ait, matrine $\left(\mathrm{C}_{15} \mathrm{H}_{24} \mathrm{~N}_{2} \mathrm{O}\right)$ also exhibits a variety of biological activities such as anti-inflammation, antivirus, anti-fibrosis, anti-arrhythmia and immunosuppression [7]. Moreover, recent studies have reported that matrine also possesses antitumor activities by inhibiting proliferation and inducing apoptosis against a wide range of cancers, including lung cancer, gastric cancer, breast cancer and so on [8-14]. Accordingly, our previous study demonstrated that matrine significantly inhibited growth of human nasopharyngeal carcinoma cells in a dose- and timedependent manner. However, the cell viability in CNE2 cells was decreased by about $50 \%$ only at high dose $(1.5 \mathrm{mg} / \mathrm{ml})$ that might not be achievable in vivo. In order to improve the anti-tumour activity of matrine with less toxicity, we synthesized a derivative from matrine, 14-thienyl methylene matrine $\left(\mathrm{C}_{20} \mathrm{H}_{26} \mathrm{~N}_{2} \mathrm{OS}\right.$, YYJ18 for short, Fig.1), which has been applied for a patent with application number CN201010188491.9 [15]. In present study, we focused on whether YYJ18 could exert inhibitory effect on growth of NPC cells in vitro at relatively low concentration, as well as the underlying mechanism.

The molecular mechanism responsible for matrine-induced apoptosis involves activation of mitochondrial and Fas/FasL pathways, partially through regulation of Akt-NF-kB signaling and caspase cascade $[9,10,14,16]$. And we have demonstrated that inactivation of vascular endothelial growth factor-A (VEGF-A)/ERK1/2 pathway also contributed to the inhibitory effect of matrine on human nasopharyngeal carcinoma cells. We thus hypothesized that MAPK and PI3K/Akt pathways may also play a role in YYJ18-mediated growth suppression of NPC cells. Our findings provide a foundation for clinical application of YYJ18 in treating nasopharyngeal carcinoma.

\section{Materials and Methods}

\section{Reagents}

YYJ18 (purity > $98 \%$ ) was provided by Dr Wang Lisheng (Guangxi University, Nanning, Guangxi, China) [15]. YYJ18 was dissolved in dimethyl sulfoxide (DMSO) to make a 1 M stock solution and stored at $4^{\circ} \mathrm{C}$ for further use. The final concentration of DMSO did not exceed $0.4 \%$ in cell culture.

\section{Cell culture}

Human NPC cell lines (CNE1, CNE2 and HONE1) were obtained from Cancer Research Institute of Central South University (Changsha, China). Cells were cultured in growth medium (RPMI-1640 medium, $10 \%$ fetal bovine serum, $100 \mathrm{kU} / \mathrm{l}$ penicillin, $100 \mathrm{mg} / \mathrm{l}$ streptomycin) at $37^{\circ} \mathrm{C}, 5 \% \mathrm{CO}_{2}$ and a humidified atmosphere.

\section{Cell viability assay}

The antiproliferative effect of YYJ18 on NPC cells was determined by [3-(4, 5-dimethylthiazol-2-yl)-2, 5 -diphenyltetrazolium bromide] (MTT) assay. Cells were plated at a density of $3 \times 10^{3}$ cells/well into a 96well plate and treated with YYJ18 for $48 \mathrm{~h}$ at various concentrations $(0,50,100,200,400,600 \mu \mathrm{M})$. Then 20 
$\mu \mathrm{l}$ of $5 \mathrm{mg} / \mathrm{ml}$ MTT (Sigma, St Louis, MO, USA) were added to each well, followed by incubation for $4 \mathrm{~h}$ at $37^{\circ} \mathrm{C}$. The supernatants were removed and $150 \mu \mathrm{L}$ DMSO was added to each well for the colorimetric reaction. Finally, the optical density was measured at $570 \mathrm{~nm}$ with a microculture plate reader (Thermo Scientific, Rockford, IL, USA).

Flow cytometry assay

Cell apoptosis was determined by flow cytometry using the Annexin V-FITC apoptosis
Fig. 1. The chemical structure of YYJ18. The molecular formula of YYJ18 is $\mathrm{C}_{20} \mathrm{H}_{26} \mathrm{~N}_{2} \mathrm{OS}$, and its molecular weight is

$342 \mathrm{kDa}$.

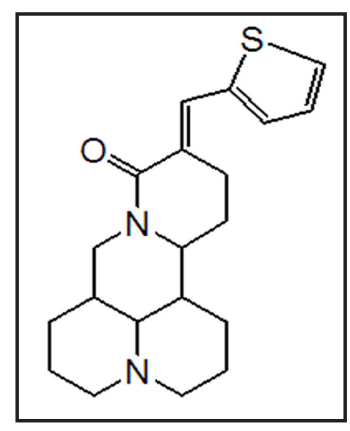

detection kit (MultiSciences, Zhejiang, China). After incubated with YYJ18 (0, 50, 100, $200 \mu \mathrm{M})$ for $48 \mathrm{~h}$, CNE2 cells were harvested and washed with cold PBS. Subsequently, cells were stained with Annexin V-FITC and propidium iodide (PI) for $5 \mathrm{~min}$ at room temperature. The early apoptotic cells (Annexin V-positive and PI-negative) were detected and quantified using FACS Calibur Flow Cytometer (Becton Dickinson, San Jose, CA, USA).

\section{Quantitative RT-PCR ( $q R T-P C R$ )}

Total RNA was extracted from YYJ18-treated CNE2 cells using TRIzol reagent (Invitrogen, Carlsbad, CA, USA) and quantified by spectrophotometry. Next, $1 \mu \mathrm{g}$ of total RNA was reverse transcribed with the RevertAidTM First-Strand cDNA Synthesis Kit (Fermentas, Maryland, USA) according to the manufacturer's instructions. The sequences of primers were as follows: Bax: 5'-ATGGACGGGTCCGGGGAGCA-3' (sense), and 5'-TGCTCGATCCTGGATGAAACCCT-3' (anti-sense); Bcl-2: 5'-TCGCCCTGTGGATGACTGAG-3' (sense) and 5'-CAGAGTCTTCAGAGACAGCCAGGA-3' (anti-sense); GAPDH: 5'-GCACCGTCAAGGCTGAGAAC-3' (sense) and 5'-TGGTGAAGACGCCAGTGGA-3' (anti-sense). Quantitative RT-PCR was performed with a SYBR Green PCR kit (Roche, Mannheim, Germany) using the StepOnePlus ${ }^{\mathrm{TM}}$ Real-Time PCR System (Life Technoligies, Carlsbad, NM, USA). The expression changes of genes were calculated using the $\triangle$ Ct method with GAPDH as internal control.

\section{Western bolt analysis}

After the treatment of YYJ18, CNE2 cells were harvested and lysed in ice-cold lysis buffer. By centrifugation for $15 \mathrm{~min}$ at $12,000 \mathrm{~g}$ and $4^{\circ} \mathrm{C}$, the supernatants were collected and determined by BCA protein assay kit (Beyotime, Jiangsu, China). Equal amounts of protein ( $40 \mu \mathrm{g}$ ) were separated by SDSPAGE and transferred to polyvinylidene difluoride (PVDF) membranes ( $0.45 \mu \mathrm{m}$, Millipore, MA, USA). The membranes were blocked with Tris buffered saline containing 0.1\% Tween-20 (TBST) and 5\% skim milk powder, and incubated overnight at $4^{\circ} \mathrm{C}$ with primary antibodies as follows: p-ERK1/2, ERK1/2, p-p38, p38, p-Akt, Akt, Bcl-2, caspase-3, Bax and GAPDH. Among them, antibodies against p-ERK1/2, ERK1/2, p-p38, p38, p-Akt and Akt were purchased from Cell Signaling Technology (Danvers, MA, USA) and used at a concentration of 1:1,000, while antibodies against Bcl-2, caspase-3, Bax from Proteintech Group (Chicago, IL, USA) at 1:1,000 and GAPDH from KangChen, (Shanghai, China) at 1:10,000. After washed with TBST, the membranes were further incubated with HRP-conjugated secondary antibody $(1: 1,000$, Cell Signaling Technology, MA, USA) for $1 \mathrm{~h}$ at room temperature, and finally developed with an electrochemiluminescence system (ECL) (Thermo Fisher Scientific, MA, USA). The densitometry of the protein bands were measured using the Gel Image Analysis system (UVP) and normalized to their relevant controls.

\section{Statistics}

Data were shown as mean \pm SD. Differences between groups were analyzed using one-way ANOVA. A p-value $<0.05$ was considered statistically significant.

\section{Results}

YYJ18 decreased cell viability in NPC cells

Three human NPC cell lines CNE1, CNE2 and HONE1 were observed to assess the effect of YYJ18 on growth of nasopharyngeal carcinoma. As shown in Fig. 2, when compared with 
Fig. 2. Effect of YYJ18 on cell proliferation of human CNE2 (A), CNE1 (B) and HONE1 (C) cells. Cells were separately treated with indicated concentrations of YYJ18 for $48 \mathrm{~h}$. And then MTT assay was used to determine cell viability. Data are representative of ten independent experiments. ${ }^{*} \mathrm{p}<$ 0.05 vs. control vehicle group $(0 \mu \mathrm{M})$.
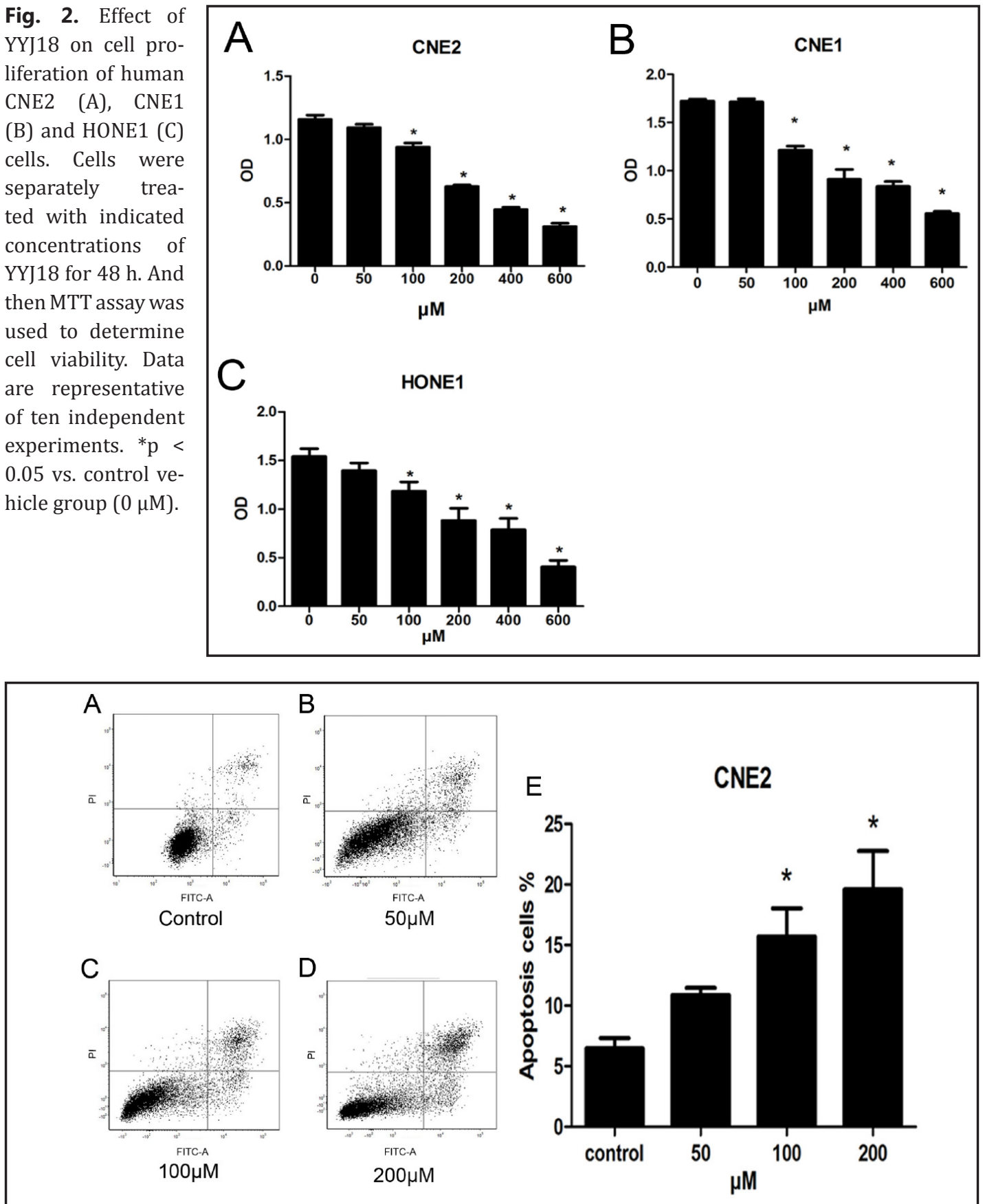

Fig. 3. YYJ18 induced apoptosis in CNE2 cells. CNE2 cells were separately treated with $0 \mu \mathrm{M}(\mathrm{A}), 50 \mu \mathrm{M}(\mathrm{B})$, $100 \mu \mathrm{M}$ (C) and $200 \mu \mathrm{M}$ (D) YYJ18 for $48 \mathrm{~h}$. Cells were then stained with Annexin V-FITC and PI, and apoptosis rate (E) were detected by flow cytometry. Data are representative of three independent experiments. ${ }^{*} \mathrm{p}<0.05$ vs. control vehicle group $(0 \mu \mathrm{M})$.

control vehicle group $(0 \mu \mathrm{M})$, YYJ18 markedly inhibited proliferation of all tested cell lines in a dose-dependent manner $(p<0.05)$, which was most pronounced in CNE2 cells with 600 $\mu \mathrm{M}$, indicating that YYJ18 could suppress the growth of NPC cell types in vitro. Also, here the highest concentration of YYJ18 was $600 \mu \mathrm{M}$, much lower than reported dose of matrine (1.5 $\mathrm{mg} / \mathrm{ml}$ ) in our previous studies. It implied that 14-thienyl methylene matrine might provide better outcomes and less toxicity than matrine. 
Fig. 4. Dosedependent or time-dependent regulation of MAPK and PI3K/ Akt pathways in YYJ18-treated CNE2 cells. Cells were incubated with various concentrations of YYJ18 for $48 \mathrm{~h}$ or $200 \mu \mathrm{M}$ YYJ18 for $0,24,48,72$ and $96 \mathrm{~h}$. Then the levels of p-Akt (A), p-p38 (B) and p-ERK1/2 (C, D) was quantitated by Western blot. The antibodies to total Akt, p38 and ERK1/2 served as loading controls. Data are representative of three independent experiments. ${ }^{*} \mathrm{p}<0.05$ vs. control vehicle group $(0 \mu \mathrm{M}$ or $0 \mathrm{~h}$ ).

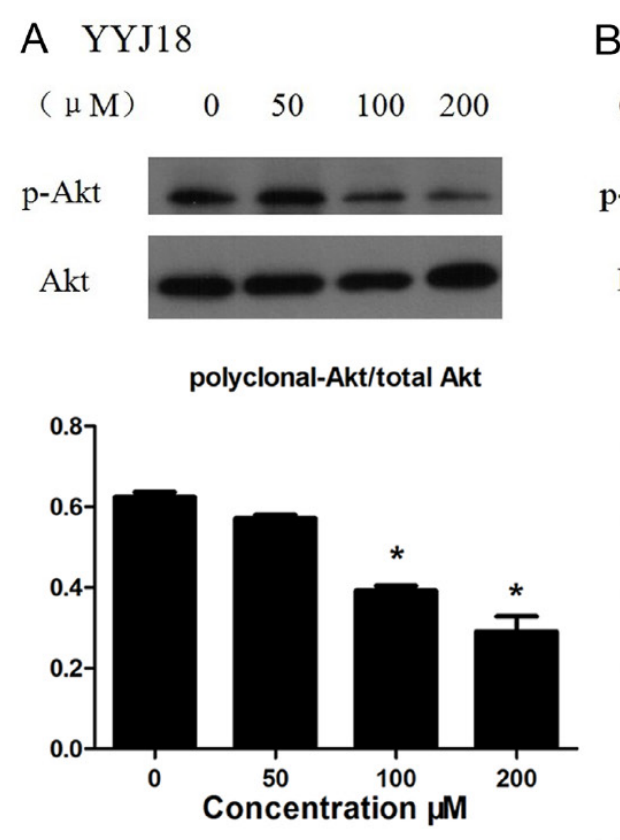

C

YYJ18

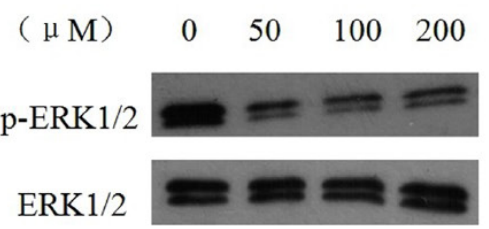

polyclonal-Akt/total Akt

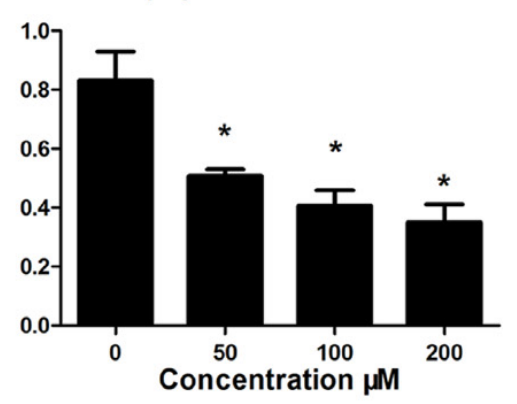

B YYJ18

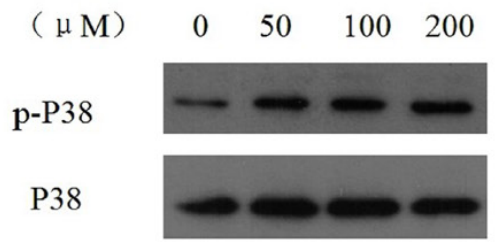

polyclonal-P38/total P38

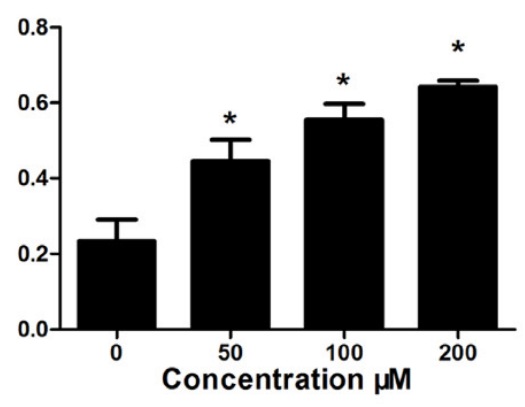

D

\section{YYJ18 $(200 \mu \mathrm{M})$}

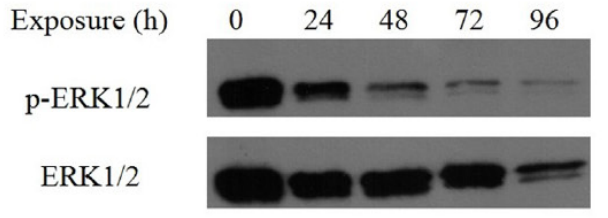

polyclonal-ERK1/2/total ERK1/2

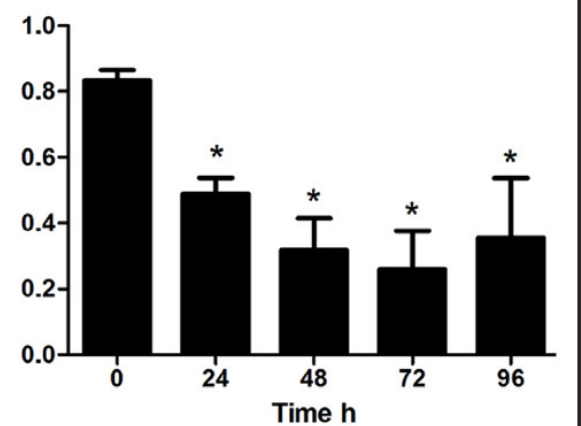

YYJ18 induced apoptosis in CNE2 cells

Given the promising results for CNE2 cells, we incubated CNE2 cells with YYJ18 for follow-up analysis. Treatment with YYJ18 in CNE2 cells resulted in significant induction of apoptosis by $10.87 \%$ in $50 \mu \mathrm{M}$ group, $15.7 \%$ in $100 \mu \mathrm{M}$ group and $19.6 \%$ in $200 \mu \mathrm{M}$ group (Fig. 3). And even at the lowest concentration level $(50 \mu \mathrm{M})$, the percentage of early apoptotic cells was still higher than control vehicle group (6.47\%), though no significant difference was observed between them. It was indicated that YYJ18 could dose-dependently trigger apoptosis in CNE2 cells, consistent with the results from MTT assay.

YYJ18 activated phosphorylation of p38 and inhibited phosphorylation of ERK1/2, Akt in CNE2 cells

To identify whether MAPK and PI3K/Akt pathways are involved in YYJ18-induced apoptosis, the expression levels of p-ERK1/2, p-p38 and p-Akt in CNE2 cells were tested by 
Fig. 5. Expression of Bax, Bcl-2 and caspase-3 in YYJ18treated CNE2 cells. Cells were incubated with $0 \mu \mathrm{M}, 50 \mu \mathrm{M}$, $100 \mu \mathrm{M}$ and $200 \mu \mathrm{M}$ YYJ18 for $48 \mathrm{~h}$. Then protein levels of caspase-3, Bax and Bcl2 were determined by Western blot (A). And the expression of Bax and Bcl-2 mRNA were detected by qRT-PCR (B). The antibodies to GAPDH (36 kDa) and GAPDH mRNA was respectively used as internal control to normalize Western blot or qRT-PCR. Data are representative of three independent experiments. *p < 0.05 vs. control vehicle group $(0 \mu \mathrm{M})$.
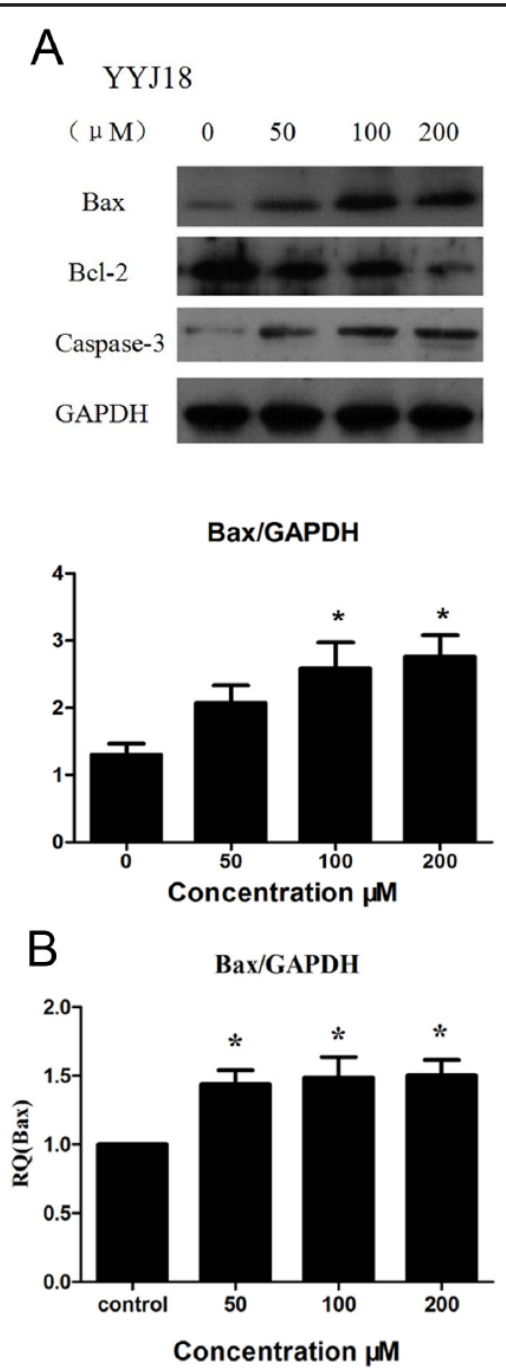

Caspase-3/GAPDH

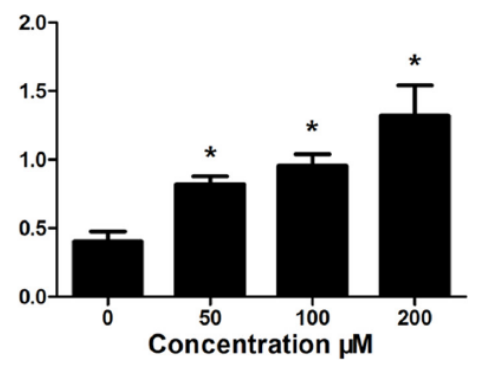

Bcl-2/GAPDH

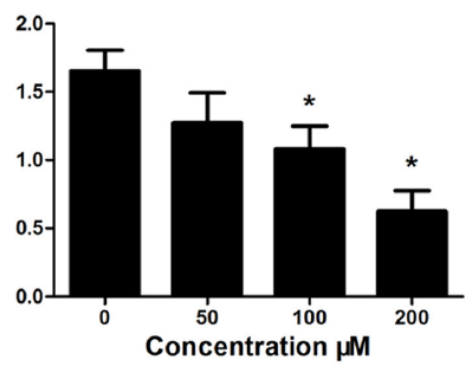

Bcl-2/GAPDH

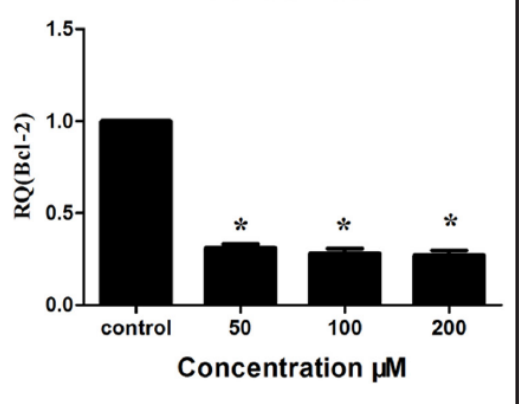

Western blot. When cells were incubated with different concentrations of YYJ18 for $48 \mathrm{~h}$, YYJ18 dose-dependently reduced phosphorylation levels of Akt and ERK1/2 compared with vehicle $(\mathrm{p}<0.05)$, but promoted phosphorylation of p38 (Fig. 4). Then we exposed CNE2 cells to $200 \mu \mathrm{M}$ YYJ18 for $0,24,48,72$ and $96 \mathrm{~h}$, so as to explore time dependence of YYJ18mediated regulation. It was found that the expression levels of $\mathrm{p}$-ERK1/2 protein gradually declined and reached a plateau at $72 \mathrm{~h}$. These results suggest that YYJ18 may stimulate apoptosis in NPC cells through regulation of MAPK and PI3K/Akt pathways.

YYJ18 increased Bax and caspase-3 expression but suppressed Bcl-2 expression in CNE2 cells

To further elucidate how YYJ18 induces apoptosis, downstream molecules of MAPK and PI3K/Akt pathways were investigated. In YYJ18-treated CNE2 cells, activation of MAPK and PI3K/Akt pathways led to dose-dependent downregulation of antiapoptotic Bcl-2 both at mRNA and protein expression levels, whereas proapoptotic Bax was upregulated (Fig. 5). Meanwhile, the levels of apoptotic executor caspase-3 protein in CNE2 cells were elevated with the concentration of YYJ18 (Fig. 5A). Therefore, we concluded that Bax, Bcl-2 and caspase-3 might be downstream targets of MAPK and PI3K/Akt pathways, resulting in YYJ18-mediated apoptosis of CNE2 cells. 


\section{Discussion}

Apoptosis is a tightly regulated cell suicide process that plays a critical role in the development and maintenance of tissue homeostasis. Due to uncontrolled proliferation of cancer cells, one of the important properties of anticancer drugs is thought to be successful proliferation inhibition and apoptosis induction $[17,18]$. It is reported that promotion of apoptosis is partially responsible for cancer suppression caused by some dietary phytochemicals such as matrine, which provides a new therapeutic strategy for reducing the incidence of cancers [19-22]. However, several experimental studies showed that not all phytochemicals are good options to prevent the development of cancers because of underwhelming anticancer activities and toxicity problems. Matrine is a natural compound extracted from Sophora flavescens Ait and exhibits antitumor activities in various cancer cell lines. Similarly, we have demonstrated that matrine inhibited proliferation and induced apoptosis of NPC cells in vitro, but the concentration $(1.5 \mathrm{mg} / \mathrm{ml})$ was so high that may not be achieved in the clinical experiment. So we synthesized 14-thienyl methylene matrine to reduce the dose and the possible toxicity. Considering that 14-thienyl methylene matrine is a derivative from martine, we speculated that YYJ18 could also exert inhibitory effect on growth of tumor cells. The present study aimed to investigate the effect of YYJ18 on NPC cells. As shown in the MTT assay, the proliferation of CNE1, CNE2 and HONE1 cells was all markedly inhibited in a dose-dependent manner when treated with YYJ18. Furthermore, the pro-apoptotic properties of YYJ18 were determined by flow cytometry. The results revealed that YYJ18 was able to dose-dependently promote apoptosis of CNE2 cells, suggesting that YYJ18 may be a potential candidate agent for treatment of NPC.

To explore the mechanisms through which YYJ18 induce apoptosis, the changes in the expression of several apoptosis-related proteins were examined in CNE2 cells in the present study. MAPK signaling pathway participates in diverse cellular activities, including cell proliferation, differentiation and survival $[23,24]$. MAPKs mainly consists of ERK1/2, c-Jun N-terminal kinases (JNKs) and p38 MAPKs. It has been confirmed that inactivation of ERK1/2 and activation of p38 are involved in triggering mitochondrial-mediated apoptosis in cancer cells $[25,26]$. In accordance with these findings, we here found that YYJ18 inhibited phosphorylation of ERK1/2 in CNE2 cells in a dose- and time-dependent manner. On the contrary, dose-dependently increased p38 phosphorylation was observed with treatment of YYJ18. Besides MAPK pathway, PI3K/Akt pathway also plays an important part in cellular growth, metabolism, proliferation, survival, migration and apoptosis [27]. As a major downstream kinase of PI3K, p-Akt is a well-known anti-apoptotic protein, downregulation of which can prevent the development of cancer [28]. Accordingly, when CNE2 cells were pretreated with YYJ18, the expression levels of p-Akt were reduced in dose-dependent manner. Therefore, we believe that YYJ18-induced apoptosis of NPC cells is achieved through selective regulation of MAPK pathway and inactivation of PI3K/Akt pathway.

Next, we detected activity changes of downstream targets of MAPK and PI3K/ Akt pathways. Bcl-2 protein family could control the outer mitochondrial membrane permeabilization, regulate cytochrome $\mathrm{C}$ release in the cytosol, and finally alter the activities of caspases [29]. The Bcl-2 family members can be divided into anti-apoptotic proteins (e.g. Bcl-2, Bcl-XL and Mcl-1) and pro-apoptotic proteins (e.g. Bax and Bak), which determines the commitment of cells to apoptosis [30,31]. Both MAPK and PI3K/Akt pathways can phosphorylate and regulate the expression of $\mathrm{Bcl}-2$ and Bax. It is demonstrated that inactivation of ERK1/2 and activation of p38, Akt could subsequently mediate upregulation of Bax and downregulation of Bcl-2, activate caspase-3 expression, and finally trigger the apoptotic pathway [32-34]. In present study, following selective regulation of MAPK and PI3K/Akt pathways, YYJ18 significantly enhanced Bax expression and suppressed Bcl-2 expression. In addition to this, the caspase- 3 protein was increased in the apoptotic NPC cells with treatment of YYJ18, confirming that Bax, Bcl-2 and caspase-3 function as downstream targets of MAPK and PI3K/Akt signaling pathways. 
In conclusion, we verified that YYJ18 was able to suppress NPC cells proliferation and induce apoptosis in vitro. The underlying mechanism involves regulation of MAPK and PI3K/Akt pathways, modulation of Bcl-2 and Bax, and final activation of caspase-3. These findings suggest that YYJ18 may have wide therapeutic application in the treatment of human nasopharyngeal carcinoma.

\section{Acknowledgements}

The funding for this research work was provided by the National Natural Science Foundation of China (81241113), Specialized Research Fund for the Doctoral Program of Higher Education of China (20094503110003) and Medical Scientific Research Center, Guangxi Medical University (KFJJ 2010-12).

\section{References}

1 Xu T, Tang J, Gu M, Liu L, Wei W, Yang H: Recurrent nasopharyngeal carcinoma: a clinical dilemma and challenge. Curr Oncol 2013;20:e406-419.

2 Lee AW, Lin JC, Ng WT: Current management of nasopharyngeal cancer. Semin Radiat Oncol 2012;22:233244.

3 Loyo M, Brait M, Kim MS, Ostrow KL, Jie CC, Chuang AY, Califano JA, Liegeois NJ, Begum S, Westra WH, Hoque MO, Tao Q, Sidransky D: A survey of methylated candidate tumor suppressor genes in nasopharyngeal carcinoma. Int J Cancer 2011;128:1393-1403.

- Fang EF, Zhang CZ, Ng TB, Wong JH, Pan WL, Ye XJ, Chan YS, Fong WP: Momordica charantia lectin, a type ii ribosome inactivating protein, exhibits antitumor activity toward human nasopharyngeal carcinoma cells in vitro and in vivo. Cancer Prev Res (Phila) 2012;5:109-121.

5 Zhang L, Chen QY, Liu H, Tang LQ, Mai HQ: Emerging treatment options for nasopharyngeal carcinoma. Drug Des Devel Ther 2013;7:37-52.

6 Wang H, Lu Y, Chen J, Li J, Liu S: Subcritical water extraction of alkaloids in Sophora flavescens Ait. and determination by capillary electrophoresis with field-amplified sample stacking. J Pharm Biomed Anal 2012;58: 146-151.

7 Guo LF, Tong SS, Yu JN, Xu XM: Advance in studies on anti-tumor mechanism of matrine. Zhongguo Zhong Yao Za Zhi 2013;38:3409-3412.

8 Zhang Y, Zhang H, Yu P, Liu Q Liu K, Duan H, Luan G, Yagasaki K, Zhang G: Effects of matrine against the growth of human lung cancer and hepatoma cells as well as lung cancer cell migration. Cytotechnology 2009;59:191-200.

-9 Dai ZJ, Gao J, Ji ZZ, Wang XJ, Ren HT, Liu XX, Wu WY, Kang HF, Guan HT: Matrine induces apoptosis in gastric carcinoma cells via alteration of fas/fasl and activation of caspase-3. J Ethnopharmacol 2009;123:91-96.

10 Yu P, Liu Q, Liu K, Yagasaki K, Wu E, Zhang G: Matrine suppresses breast cancer cell proliferation and invasion via VEGF-Akt-NF-kappaB signaling. Cytotechnology 2009;59:219-229.

11 Zhang P, Wang Z, Chong T, Ji Z: Matrine inhibits proliferation and induces apoptosis of the androgenindependent prostate cancer cell line pc-3. Mol Med Rep 2012;5:783-787.

12 Liu XY, Fang H, Yang ZG, Wang XY, Ruan LM, Fang DR, Ding YG, Wang YN, Zhang Y, Jiang XL, Chen HC: Matrine inhibits invasiveness and metastasis of human malignant melanoma cell line a375 in vitro. Int J Dermatol 2008;47:448-456.

-13 Liang CZ, Zhang JK, Shi Z, Liu B, Shen CQ Tao HM: Matrine induces caspase-dependent apoptosis in human osteosarcoma cells in vitro and in vivo through the upregulation of bax and fas/fasl and downregulation of bcl-2. Cancer Chemother Pharmacol 2012;69:317-331.

14 Zhang S, Zhang Y, Zhuang Y, Wang J, Ye J, Zhang S, Wu J, Yu K, Han Y: Matrine induces apoptosis in human acute myeloid leukemia cells via the mitochondrial pathway and akt inactivation. PloS one 2012;7:e46853.

15 Wang L, You Y, Wang S, Liu X, Liu B, Wang J, Lin X, Chen M, Liang G, Yang H: Synthesis, characterization and in vitro anti-tumor activities of matrine derivatives. Bioorg Med Chem Lett 2012;22:4100-4102. 
16 Liu XS, Jiang J, Jiao XY, Wu YE, Lin JH: Matrine-induced apoptosis in leukemia u937 cells: involvement of caspases activation and mapk-independent pathways. Planta Med 2006;72:501-506.

17 Plati J, Bucur 0, Khosravi-Far R: Apoptotic cell signaling in cancer progression and therapy. Integr Biol (Camb) 2011;3:279-296

18 Koehler BC, Jäger D, Schulze-Bergkamen H: Targeting cell death signaling in colorectal cancer: Current strategies and future perspectives. World J Gastroenterol 2014;20:1923-1934.

19 Paulraj J, Govindarajan R, Palpu P: The genus spilanthes ethnopharmacology, phytochemistry, and pharmacological properties: a review. Adv Pharmacol Sci 2013;2013:510298.

20 Huang TT, Liu FG, Wei CF, Lu CC, Chen CC, Lin HC, Ojcius DM, Lai HC: Activation of multiple apoptotic pathways in human nasopharyngeal carcinoma cells by the prenylated isoflavone, osajin. PloS One 2011;6:e18308.

21 Tian J, Duan YX, Bei CY, Chen J: Calycosin induces apoptosis by upregulation of RASD1 in human breast cancer cells MCF-7. Horm Metab Res 2013; 45:593-598.

22 Liu T, Song Y, Chen H, Pan S, Sun X: Matrine inhibits proliferation and induces apoptosis of pancreatic cancer cells in vitro and in vivo. Biol Pharm Bull 2010;33:1740-1745.

23 Tulalamba W, Janvilisri T: Nasopharyngeal carcinoma signaling pathway: An update on molecular biomarkers. Int J Cell Biol 2012;2012:594681.

24 Chen J, Hou R, Zhang X, Ye Y, Wang Y, Tian J: Calycosin suppresses breast cancer cell growth via ER $\beta$ dependent regulation of IGF-1R, p38 MAPK and PI3K/Akt pathways. PLoS One 2014;9:e91245.

25 Zhang Z, Miao L, Lv C, Sun H, Wei S, Wang B, Huang C, Jiao B: Wentilactone B induces G2/m phase arrest and apoptosis via the Ras/Raf/MAPK signaling pathway in human hepatoma SMMC-7721 cells. Cell Death Dis 2013;4:e657.

-26 Min L, He B, Hui L: Mitogen-activated protein kinases in hepatocellular carcinoma development. Semin Cancer Biol 2011;21:10-20.

27 Pal I, Mandal M: PI3k and Akt as molecular targets for cancer therapy: current clinical outcomes. Acta Pharmacol Sin 2012;33:1441-1458.

28 Chen J, Zeng J, Xin M, Huang W, Chen X: Formononetin induces cell cycle arrest of human breast cancer cells via IGF1/PI3K/Akt pathways in vitro and in vivo. Horm Metab Res 2011;43:681-686.

29 Spencer SL, Sorger PK: Measuring and modeling apoptosis in single cells. Cell 2011;144:926-939.

-30 Shamas-Din A, Kale J, Leber B, Andrews DW: Mechanisms of action of bcl-2 family proteins. Cold Spring Harb Perspect Biol 2013;5:a008714.

-31 Medina-Ramirez CM, Goswami S, Smirnova T, Bamira D, Benson B, Ferrick N, Segall J, Pollard JW, Kitsis RN: Apoptosis inhibitor ARC promotes breast tumorigenesis, metastasis, and chemoresistance. Cancer Res 2011;71: 7705-7715.

32 Ye Y, Hou R, Chen J, Mo L, Zhang J, Huang Y, Mo Z: Formononetin-induced apoptosis of human prostate cancer cells through ERK1/2 mitogen-activated protein kinase inactivation. Horm Metab Res 2012;44:263267.

33 Kim EK, Choi EJ: Pathological roles of MAPK signaling pathways in human diseases. Biochim Biophys Acta 2010; 1802:396-405.

-34 Frejlich E, Rudno-Rudzińska J, Janiszewski K, Salomon L, Kotulski K, Pelzer O, Grzebieniak Z, Tarnawa R, Kielan W: Caspases and their role in gastric cancer. Adv Clin Exp Med 2013;22:593-602. 